\title{
LESSONS FROM DEPLOYING LARGE-SCALE SOLAR ELECTRIFICATION IN BANGLADESH: CAN THE LAST MILE BECOME THE FIRST?
}

\author{
GEORG HEINEMANN, RALUCA DUMITRESCU, CHRISTIAN VON HIRSCHHAUSEN, \\ NOARA KEBIR \& DANIEL PHILIPP \\ TU Berlin, Microenergy Systems Research Group, Germany
}

\begin{abstract}
With over four million solar home systems (SHSs) deployed, Bangladesh stands out in the development of decentral, bottom-up electrification. Amid a difficult socio-economic and political environment, joint efforts by local authorities, financing institutions, entrepreneurs and engineers, supported by international donors, a community-based infrastructure development, largely based on local value creation, has succeeded. This paper discusses the success factors of the Bangladeshi SHS development over the last two decades and its current ambitions, focussing on the organizational models deployed, amongst others, on value-added production and financing. We then provide a critical assessment of the perspectives to make the last mile the first one, i.e. to use SHS as the driver of decentral, yet grid-based electrification. Last but not least, we give an outlook towards the potential of "swarm electrification", i.e. the bottom-up (r)evolution of the energy infrastructure by interconnecting existing and new electricity usages, storages and generation, enabling a peer economy based on prosumerism and local value creation.

Keywords: bottom-up electrification, off-grid organizational model, IDCOL SHS program, decentral infrastructure development, microgrid, swarm electrification, last-mile distribution.
\end{abstract}

\section{INTRODUCTION}

Since its independence from Pakistan in 1971, the country of Bangladesh has been challenged by its small size, its limited resources and a population density, which makes it one of the most populous countries in the world. Although its socio-economic situation has substantially been improving over the last years, Bangladesh is still ranked 139 out of 188 countries on the human development index. In rural Bangladesh, where more than $60 \%$ of the population lives, it was in principal too laborious and expensive to extend the national electricity grid [1]. As a result, $42.49 \%$ of them had still no access to electricity in 2010 [2]. Six years later, the access rate has almost doubled and an access to electricity rate of $69 \%$ in rural Bangladesh can be noted [3]. The key pillar of this achievement is the large-scale and decentral deployment of solar home systems (SHSs). Already back in 2003, Bangladeshi authorities initiated a publicly co-funded SHS loan program, managed by the public Infrastructure Development Company Limited (IDCOL). The IDCOL SHS program is characterized by local stakeholders implementing the program in a decentralized manner and by a highly standardized SHS, which is packaged with a simple consumer loan for the end-users. Over the period of almost two decades this setup, co-funded by various international development partners, has gained considerable momentum, and by 2017, more than 4 million SHSs had been installed [4]. Bangladesh has been recognized as the largest solar off-grid program as well as the country with the highest share $(9 \%)$ of total population connected to off-grid supply in the world [5].

\section{THEORETICAL BACKGROUND}

In changing and complex environments, the provision of public infrastructure such as rural electrification faces a number of challenges, such as high investment costs, continuous and 
costly maintenance and long amortising periods. Furthermore, the inherent complex nature of providing electrification on household level by using SHS implies additional high transaction costs [6]. Identifying the different elements and their characteristics as well as understanding motivation and behaviour of the involved stakeholders is the principal objective of our investigation. Thus, the starting point of our analysis is the understanding of the "system" of the public good - all the elements involved to provide rural electricity by deploying solar systems on household level. Its complexity requires distinguishing between the various parts of this task. Beckers et al. [7] define the provision of a public good as a transformation process with different phases. Input has to be identified, pooled and interrelated to achieve the desired output. Key elements are the technical system, actors, their assets and their roles, as well as institutions.

The technical system describes the targeted public good in combination with its characteristics such as assets and basic processes to produce the good. Actors can be individuals or organizations. They possess their own set of objectives, for example maximizing profit, as well as specific assets and capabilities which contribute to the transformation process. Actors assume roles. Roles represent packages of sub-tasks within the transformation process. Roles can be organized according to their package of tasks or according to the respective transformation phase they fit into. The nature of actors and their capabilities as well as the complexity of the technical system create interdependencies. Therefore, institutions are needed to assume the role of coordination between them. Institutions are formal or informal norms which frame the interaction between the elements, the actors and their roles.

The second dimension is the discussion of the organizational model. The provision of infrastructure such as rural electricity can be organized by the government, the private sector or by choosing a hybrid model from these two options. While researchers form a common understanding on the complexity of choosing a model for making infrastructure available, findings such as the research from Hassheider [8] on the provision of transregional road infrastructure, Ewers [9] on privatizing federal highways and Ménard and Saleth [10], which discuss alternatives for the provision of potable water, are not able to recommend a universal organizational model for public infrastructure tasks. Finding the most appropriate organizational model strongly depends on the actual characteristics of the project and the local conditions [11]. The theory of new institutional economics (NIE) is to lead to an understanding of how the strategy of institutional organization for decentralized electrification might look like. The objective of NIE is to investigate institutions and their interaction with organizational structures. Institutions describe constructs of formal and informal norms and rules, as well as the organization of their implementation within a society. This reflects the advancement of the theories of neoclassical economics. NIE not only looks at the pure rational approach of neoclassical theory, but also incorporates actual realities such as time, individual and emotional behaviour, as well as other transaction costs. Numerous scientific works already deal with new institutional economics as the underlying theory for providing public infrastructure [6], [10]-[12].

Furthermore, to classify organizational models Klatt [13] and Wealer et al. [14] distinguish between the categories provision, in which the actual need is defined, production, consisting of the transformation process of the public good, and financing. The transformation process can be further characterized as an entire value chain consisting of the five phases planning, production, distribution, operation and maintenance. The interdependencies and the structuring of these three categories is supposed to shed light on the principal question of how the decision-making process can be designed to achieve the intended output. 


\section{METHOD}

Our methodology is based on a research design which reviews existing literature on rural electrification programs as well as the theory of organizational models in public infrastructure. We apply a descriptive-longitudinal case study approach by reviewing the different stages of rural electrification in Bangladesh. The underlying objective is to discuss the development of the SHSs program in Bangladesh and its related organizational model. Our principal unit of analysis is the historic and contextual component. Among others, our analysis includes extensive findings from the World Bank [15]-[17] as well as dedicated policy research papers [1], [18]-[20] to explore the evolution of the program since its inception in 2002. Special attention is paid to involved stakeholders. While literature on business models of SHS programs is vast, the institutional perspective has received much less attention. Thus, as a second step, we explore the program according to the organizational model deployed. Lastly, we introduce swarm electrification as one solution to the recent challenges of the program. Bottom-up grid infrastructure by interconnecting solar home systems may present the next level of sustainable off-grid electrification. Our methodological concerns have consequently followed a two-stage approach. A consistent overview of the most relevant literature in Bangladesh as well as a discussion of organizational models in the field of rural electrification was reached.

\section{FINDINGS}

By analysing SHS electrification in Bangladesh over the course two decades, our study sheds light on the organizational model deployed. More specifically, our findings reveal the three critical dimensions of organizing the process of SHS deployment: (i) the production, (ii) the provision and (iii) the financing. In the sections that follow we introduce the IDCOL SHS program, map the underlying organizational model and discuss the historic development of the three dimensions in turn. Our historic analysis will be categorized according to (i) early days (2003-2008), (ii) take-off and peak (2009-2015) and (iii) recent developments (2016-present).

\subsection{The IDCOL SHS program}

The IDCOL SHS program started in Bangladesh in 2003. Since then it has been implemented by the state-owned IDCOL. Its capacity originates in its public mandate of financing infrastructure projects and in its right of extending soft loans to private companies. As a nonbanking institution ICDOL is supplied with funds by the Government on the one hand, and by international donor organisations, on the other hand. For the SHS program, IDCOL uses these funds to provide loans at non-market conditions to the Partner Organisations (POs). The POs use these funds to pre-finance the required SHS provided by the suppliers and to set up affordable consumer loans for the targeted off-grid households. The POs are the single point of contact for the households. They carry out installation, user training, maintenance and loan collection.

The program's underlying organizational model is organized according to two premises (Fig. 1): first, the elements to provide the output, rural electrification with SHSs on household level, are organized horizontally along the defined value chain. The value chain not only divides the transformation process in five phases, but also classifies the actors according to their roles during each phase. Interdependencies exist on the level between IDCOL/government and the organizations (suppliers and POs), between POs and suppliers, as well as between POs and households. Second, our three principal "organizational" dimensions are mapped, too: the financing perspective is fully organized and provided by 
IDCOL. The POs are in charge of the provision, which includes the distribution, operation and maintenance phases. They are selected and mandated by the IDCOL's PO Selection Committee. Lastly, private manufacturers are in charge of the production. IDCOL's Technical Standards Committee provides directives and approvals for them [18]-[20].

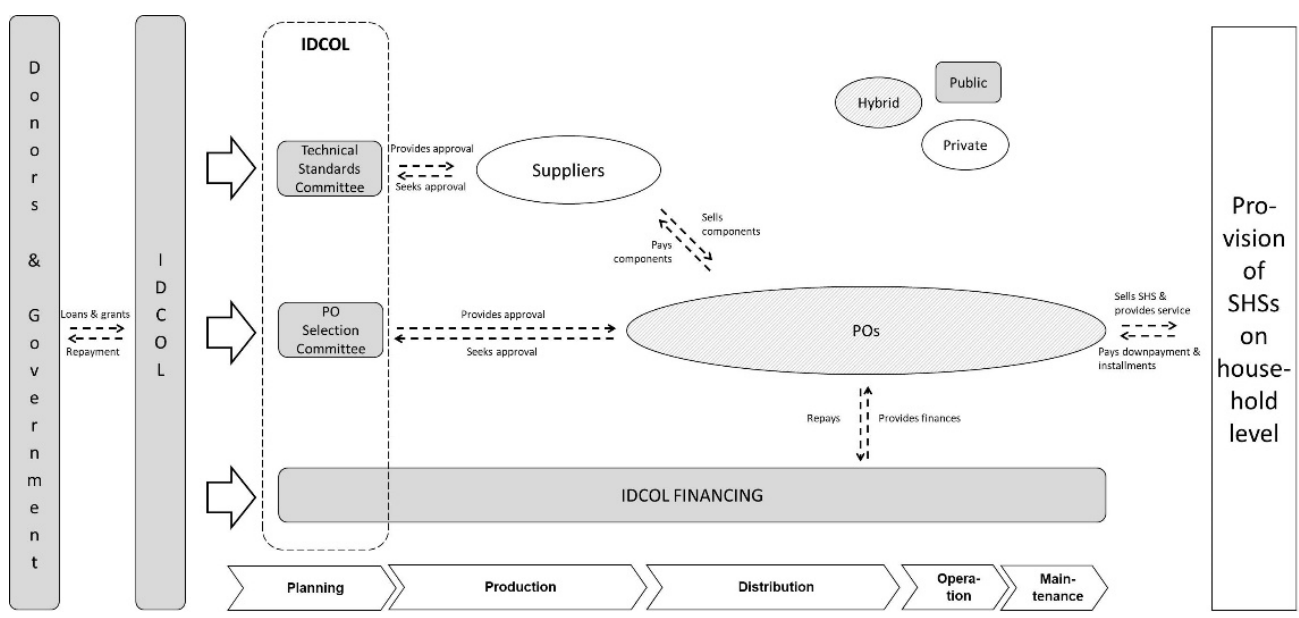

Figure 1: Organizational model of the Bangladesh SHS program. (Source: Own compilation.)

\subsection{Production}

The production perspective is principally influenced by three actors: IDCOL, local suppliers and global suppliers.

\subsubsection{Phase 1: early days}

A dedicated local industry focusing on the manufacturing and assembling of solar home systems did not exist when the program started in 2003. In 2002, the World Bank conducted a survey and concluded that only a very negligible number of battery manufacturers and fluorescent lamp producers were existent [16]. Thus, in its beginning, the program relied mostly on importing SHS components from global manufacturers based in countries like Singapore, India and China [19]. In the following IDCOL established a dedicated Technical Standards Committee (TSC). First of all, TSC was assigned with the task to manage the supply side by approving suppliers and ensuring technical standards. Procedures, inspectors and technical experts ensured minimum quality of (local) equipment and after-sales services incl. maintenance and product warranties for a minimum of 3 years. Random technical audits, a dedicated customer call center at IDCOL head office and 13 regional offices were further examples for TSC's role [17]. However, IDCOL and its executive arm TSC as its executive arm TSC started various support initiatives, too, which actually promoted the local solar industry in the end. The renewable energy authority SREDA was initiated, tax reduction and special incentives for local manufacturing of renewable products and components were introduced, private sector investment was facilitated, a national target plan for renewable energies was launched and import tariffs for assembling solar components were reduced. 


\subsubsection{Phase 2: take-off and peak}

While in the first five years of the program a total of 200,000 SHSs were installed, the real take-off started in the period 2008-2011. In just 3 years a total of 1.4 million SHSs were deployed [19]. IDCOL's policies to foster local manufacturing, which reduced end-user prices as well as improved the efficiency of the supply chain plus a substantial global decrease of solar component costs contributed to the boom.

An example for IDCOL's effective framework was the mandatory local sourcing and assembling of charge controllers. It turned out that local quality was very low at the beginning. The return rate was so high that each PO had to compulsively hold a decentralized emergency stock of $2 \%$ of their turnover available. The replacement to end-users had to be provided free at all times. Later, the emergency stock was reduced to $1 \%$. It reflected a powerful intervention to improve quality of the locally made charge controllers resulting in 53 local suppliers at the peak of the program. Various aiding measurements grew out of it, such as mandatory free emergency stock for other components, engraving customer service hotline numbers instead of stickering, as well as an overall decrease of the mean time to failure rate. They confirm the evolvement of the local solar industry during that time [1].

Another example is the local manufacturing of the battery component. Batteries are the most delicate and vulnerable part of the SHS, as they can break down quickly due to poor battery quality and management. And they may represent up to $40 \%$ of the total system cost. Managing this component well is one of the key success factors of the IDCOL program. The type of battery to be provided was stipulated by IDCOL. POs were obliged to use tubular plate lead-acid batteries. They have the benefit of allowing regular discharge of $80 \%$, featuring a higher charging efficiency and a low rate of self-discharge. Batteries were to be provided with a 5-year warranty to the end-user. As they were locally available, IDCOL decided to only approve local manufactured batteries for the program. When the program started, only 3 local suppliers were approved by IDCOL. At the peak of the program a total of 30-40 suppliers existed, 22 of them were ISO certified. Recycling schemes were enforced, too. In 2013 three recycling plants were existent highlighting IDCOL's unique battery replacement policy. POs were urged to notify SHS users 3 months prior to the estimated ceasing of the battery. They would then receive a $24 \%$ rebate on a new battery if they returned the old one. IDCOL triggered this proactive after-sales program by providing POs and battery manufacturers a USD 10 supplement for each newly installed battery plus a $100 \%$ refinancing option [19], [20].

The battery component was one of the trigger points for the take-off of the program establishing and confirming an efficient framework of quality control and customer service. Being so critical for the performance of the system, IDCOL's proactive battery management was essential for achieving positive end-user perception and in a rather short period of time rural Bangladeshis learned to trust and appreciate IDCOL's SHSs.

\subsubsection{Phase 3: recent developments}

By 2015, 31,750 jobs existed in the solar manufacturing sector. Next to $30-40$ battery suppliers, the local industry comprised of 57 LED suppliers, 53 charging controller suppliers and 9 solar panel assembly plants. While batteries, LED suppliers and charging controllers were $100 \%$ locally sourced, the local solar panel assembling covered approximately $20 \%$ of the total PV demand [19]. Nevertheless, sales of SHSs are recently slowing down and the number of jobs are slightly decreasing, too [21]-[23]. Further details and reasons will be discussed in the following section.

To sum up, the IDCOL program can be overall regarded as a strong industrial policy. Local manufacturing and jobs were created. Domestic research and development were 
fostered too. A considerable cost reduction of components was achieved. SHSs in Bangladesh cost nowadays only about $50 \%$ of SHSs available in East Africa [24]. Furthermore, the growth of the local supply side helped to improve and adjust the technology to the local needs and to introduce valuable accessories. Analysing the production perspective illustrates that implementing and fostering local manufacturing requires economic support and protectionism on local level combined with a certain time horizon.

\subsection{Provision}

Provision describes, as we have defined in the beginning, the dimension to distribute the public good in question. Looking at our organizational model, deploying SHSs in rural Bangladesh is mainly facilitated by the POs. POs are IDCOL's partner organizations that execute the distribution and installation of the SHSs on household level. POs can be different type of organizations such as for-profit SMEs, social enterprises, NGOs and MFIs. One thing they all do need to have in common: a very rural, a decentralized distribution model, with a strong presence in the countryside. Furthermore, they are regulated by the Microcredit Regulatory Authority of Bangladesh and they are guided by a well-defined Memorandums of Understanding (MoU) with IDCOL [20].

In Bangladesh, the last-mile provision of the SHSs by the POs is one of the key drivers of success.

\subsubsection{Phase 1: early days}

Grameen Shakti and BRAC were the only distributors which started operations before the IDCOL SHS program was initiated in 2003. A closer look at Grameen Shakti (GS) helps to illustrate the distributor perspective in the early days. GS is a 1996 spin-off of the well-established Grameen Bank. GS, which means in Bengali "village energy", started off with the idea to migrate the successful MFI model of Grameen Bank into the energy sector. Its business model was based on the lessons-learnt of the Grameen Bank summarized in the following three principles [25]:

1. The SHS user pays a down-payment and commits to monthly instalments.

2. GS staff provides service, incl. installation, maintenance, credit collection

3. The SHS is fully owned by the user. The fee-for-service model, which was favoured by the government at that time, was not considered.

Despite of this initial strategic alignment with their experience from the MFI sector, GS discovered key barriers to rapidly increase SHS installations. First, GS faced the challenge of providing appropriate technology for their consumer loans. Solar technology was still in its infancy in the nineties. Providing cost effective and reliable solar home systems was a major challenge to GS. Most of the components had to be imported at high cost and had to be packaged/customized as needed, although local know-how was not yet available. Second, GS struggled with low awareness for solar-technology and solving this was hampered by a substantial lack of marketing and of capacity building abilities [16]. Third, GS was not able to offer attractive conditions to its target users. GS started with a simple SHS package consisting of CFL bulbs, battery, charging controller and solar panel. The package was offered at around USD 500. Considering the limited rural income levels, GS offered the SHS on a consumer loan, but only with loan tenure of max. 12 months. These conditions depended on GS's own refinancing situation with its mother entity, the Grameen Bank. The typical MFI business model extends 1 year business loans at USD 100-200 at a 20\% interest for 
starting or refinancing micro-businesses [25]. GS could not extend very different conditions to its customers. Fourth, cost of operating a distributed SHS business model was extremely high. GS was only selling about 20 SHSs per month. The business model was rather based on low margins considering high technology cost vs. low residential purchasing power. GS could not reach economies of scales as hoped. Moreover, the complex value chain in terms of sourcing the systems, installing and delivering them to remote place as well as frequent after-sales and maintenance visits, turned the GS business case into an unappealing and unprofitable business.

\subsubsection{Phase 2: take-off and peak}

One of the major obstacles for electrification through SHSs is the establishment of a robust supply chain at an affordable end-user price. The IDCOL SHS program solved this equation by relying on the pertinent pre-program experiences of GS. IDCOL introduced an attractive refinancing scheme, which enables the POs to organize the last-mile-distribution on large scale, offering technical services (product, installation, after-sales services) and financial services (loan provision, instalment collection) to rural Bangladeshis. The POs not only benefit from increased sales but also from economies of scale as well as direct financial support for capacity building.

Competition played an important role to kick-off the program, too. The program started with only five players to test and fine-tune the model. As soon as it proved itself to be working, IDCOL introduced the strategy of excess of supply. Low entry barriers combined with start-up incentives for new distributors proved to be effective. IDCOL aspired to have as many POs as possible. The demand to be satisfied was enormous and the challenge to reach it with an efficient last-mile distribution was complex. In addition, by promoting strong competition, IDCOL was hoping to introduce an additional, self-embedded shakeout mechanism. A broad and competitive supply would quickly eliminate players offering sub-standard quality or overpriced services [20]. Asaduzzaman et al. [18] discuss the usefulness of this strategy. On the hand, it enhances quality and service. It makes sure the subsidy really reaches the end-user. They argue that GS was operating almost alone at the beginning. From 2009 onwards, more and more players joined distribution. These new entrants received more favourable financial conditions. They were able to offer more competitive products and services. Respectively, during this phase end-user prices decreased and SHS installations reached a total of 3.5 million as of December 2014. At the same time the number of active POs reached 56 and altogether they disposed of a very rural and extensive sales and after-sales network with up to 5,732 sites as of September 2015 [19].

\subsubsection{Phase 3: recent developments}

From 2013-2015 annual SHS installations have sharply decreased by 48\%. Ever since then, the installations rates have not recovered and POs are substantially affected. Reactions are mixed. Most of the POs see the entry of cheap generic products as the main root of the problem. Their bad quality is hampering the reputation of SHSs in the market. Furthermore, they are convinced that it is IDCOL responsibility to solve this issue by enforcing more restrictive quality and pricing conditions, especially on the ignored but growing generic market. Only few POs are trying to respond proactively to the challenge. An example is Rahimafrooz, the subsidiary of the biggest battery supplier in the market. Next to GS, they became the leading PO over the years. They are tackling the crisis by trying to put more emphasis on innovation. They just started to digitize the payment data of their clients. They have also introduced a sales app for its agent network and equipped all agents with smartphones. These digitization efforts are supposed to take out inefficiencies in the value 
chain, but they also hope to strengthen the relationship with their customers. They target to explore it for new and smart avenues of income such as using the digitized customer credit data for introducing banking or furniture products [26].

\subsection{Financing}

As already mentioned, when discussing the success of the POs, the financing perspective is the most critical component of the IDCOL SHS program. Effective aggregation, management and provision of funds are key drivers for successful SHS programs [15], [27]. Our historic analysis of the financing perspective focuses on the costing and raising of the required funds, embedding financial instruments into the value chain to provide access to finance wherever required, as well as on the management and control of the complete financing scheme.

\subsubsection{Phase 1: early days}

At the beginning, IDCOL joined forces with the strategic development partners German Development Cooperation (GIZ), Global Environment Facility, International Development Association, and Kreditanstalt für Wiederaufbau (KfW) to set-up a feasible financing scheme [19]. The collaboration addressed the following key components:

Management structure: Although receiving funds and technical support from the development partners, the overall management and control of the financing scheme remained in the hands of IDCOL. This approach followed the concept of external segregated fund management (Wealer et al. [14]) resulting in a centralized funds scheme managed by IDCOL with the benefits of increased fund transparency, centralized management avoiding decentral mismanagement or even bankruptcy and improved public confidence in the program.

Calculating the cost and scope of the program: Furthermore, Wealer et al. [14] defines five approaches for estimating the costing of infrastructure. The IDCOL financing approach was a blend of the specific analogy approach and the bottom-up technique. The bottom-up technique looks at the smallest components of the cost. The specific analogy compares the costing to similar projects in the past. IDCOL could rely on the experience of GS in the 1990s as well as the government projects in 1997, when a SHS pilot for 850 households in Narsingidi District was conducted, and in 2002, when the program "Diffusion of RE technologies" for 6,000 households was launched [19]. Combining both approaches IDCOL came up with a scheme to implement a microfinance-based, direct sales program. The initial scope targeted to deploy 50,000 SHS by 2008 .

Timing: The new financing scheme incorporated a soft loan facility provided by the various international development partners. Thus, IDCOL and its implementing POs were able to change the terms of its SHS consumer loans. User's repayment period was extended to three years. Consequently, POs could finance their working capital through IDCOL over a period of up to 10 years. Not only enabled this extended loan tenure households to afford the monthly instalments but also it facilitated sufficient and sustainable refinancing for the production and provision side [20].

In August 2005, the initial milestone of 50,000 SHS was already achieved, 3 years earlier than planned and USD 2 million below estimated costs [19].

\subsubsection{Phase 2: take-off and peak}

During the take-off and peak period, the specific IDCOL strategy, providing a mix of output-based subsidy, supported refinancing scheme, and institutional and technical incentives, proved to be highly efficient. Rapid take-off and solid market creation was facilitated by offering three principal financial instruments [20]: 
1. Buy-down grant: To subsidize rural electricity access on household level, IDCOL started to provide a fixed capital buy-down grant at USD 70 per system. It was an upfront grant, which went directly to the PO in the moment the installation was confirmed.

2. Refinancing: In 2003, POs were able to refinance $80 \%$ of the SHS retail price with a subsidized loan provided by IDCOL. The soft conditions were a reduced interest rate of $6 \%$ and extended loan tenure of up to 10 years. The remaining $20 \%$ of the SHS retail price had to be covered by the customer's down payment and/or be refinanced by the PO itself. This "market" component ensured that ownership for the system and the extended loan among users and POs were maintained. Furthermore, POs were able to increase their profitability by leveraging their IDCOL refinancing loan against the consumer loan. The SHS consumer loan had a higher interest rate and a shorter lending period. The resulting spread could be used to increase the profit margin.

3. Institutional grant: An institutional grant of USD 20 for each SHS installed for the POs was available in 2003. It further subsidized the affordability of the SHS, but most of all it represented a direct support for the PO to build its operational capacity over time training of employees, improving company's assets/operational infrastructure (IT, vehicle fleet) are some examples. But this subsidy was only disbursed on a cost sharing basis of $80 \%$ (IDCOL) $/ 20 \%$ (POs) on the one hand, and if the POs non-performing loan portfolio was low enough, on the other hand. In this way, IDCOL managed to include a self-embedded control mechanism to monitor the performance of its distribution partners.

Asaduzzaman et al. [18] discuss the effectiveness of the buy-down grant. The grant per SHS was fixed, favoring the price of smaller systems resulting in more affordable offerings for poorer households. However, working independently and with a direct-sales program, POs certainly did try to increase prices whenever possible. Therefore, the grant could have had the exact opposite effect in the end. The analysis concludes that competition is required to avoid the described effect, which confirms the important aspect of creating a competitive environment among POs as we have already described in Section 4.3.2.

In addition to this analysis, a closer look at the development of the financing provided by IDCOL to the POs illustrates the effectiveness of this subsidy scheme (Tiedemann [20]): With the above described conditions for PO refinancing (loan) and grant (USD/system installed), total annual installations of 11,697 SHS were reached in 2003. Already in 2004 both grant components were reduced for the first time and were gradually phased out in the following years. In 2013, while refinancing for the POs remained at similar conditions, the grant component was almost non-existent, only a fixed USD 20 subsidy for systems $<30 \mathrm{Wp}$ remained. However, the annual installations reached an all-time high of a total of 852,388 SHS. Although Tiedemann's [20] calculation is only an approximation, it illustrates the importance of the refinancing loan. In the moment the maturity of the loan was largely extended SHSs installations increased drastically over the course of the years. Reducing the fixed grant subsidy per system installed from USD 90 in 2003 to almost zero on the contrary, did not have any negative effect at all.

\subsubsection{Phase 3: recent developments}

Over the years, the program has substantially increased its scope. It is nowadays supported by a variety of development partners including the Asian Development Bank (ADB), Department for International Development of the United Kingdom, GIZ, Global 
Environment Facility, Global Partnership on Output-Based Aid (a multidonor trust fund), Islamic Development Bank, Japan International Cooperation Agency, KfW, SNV, United States Agency for International Development, and World Bank. The financing scheme was extended several times. Its total targeted investment of USD 191 million at the beginning has reached more than USD 700 million by now providing over 4 million households with electricity access. Reflecting an estimated cost to government of USD 170/SHS installed, the IDCOL program is not only one of the largest but also one of the most cost-effective programs in the world [4], [26].

Drawing on this historic overview, our analysis demonstrates that the IDCOL financing scheme has been pivotal for the scale and outreach of SHS installations in Bangladesh. By centrally managing the funds, adapting loan conditions on PO and household level to the actual needs, the program has been successful in setting up a SHS market for more than four million users.

\section{OUTLOOK}

On 21st of November 2017, the United Nations Department of Economic and Social Affairs awarded two companies in Bangladesh the "Powering the Future We Want" prize for their joint project that allows villagers to secure more solar power, save money through flexible energy access, and generate income from trading electricity [28]. The two companies, a solar technology developer and the largest PO, Grameen Shakti, interconnect existing SHS into peer-to-peer (P2P) swarm microgrids, allowing end-users to trade the self-generated surplus electricity among each other, in a process called Swarm Electrification. Swarm Electrification is the bottom-up evolution of the energy infrastructure by interconnecting individual existing and new electricity usages, storages and generations, enabling a local shared economy based on prosumerism and local value creation. Through these P2P swarm microgrids, network effects are generated through the inclusion of local economies with strong producer-consumer linkages embedded within larger systems of trade and exchange.

Although the P2P energy concept is more often encountered in the Global North, due to its particular energy infrastructure developed through the IDCOL SHS program, Bangladesh is the first country in which the initiative was implemented. The pre-existence and the density of the standardized and quality certified standalone energy systems constitute the technical infrastructure as the basis for Swarm Electrification. However, within this vast network of SHS, the households do not fully utilize the electricity stored in their battery, resulting in a full battery by midday, limiting the generation potential of their systems. At the same time, other households and businesses require electricity beyond what their systems can supply but cannot afford the acquisition of a new solar system. Through the P2P swarm microgrids, households and businesses are interconnected bottom-up, granting for the trading of the locally generated electricity through blockchain based applications. Such grids grow incrementally towards the national grid, allowing communities that would otherwise represent the last mile of rural electrification to become the first mile. The economic infrastructure of Swarm Electrification is represented by the paradigm shift in electricity consumption - consumers are transformed in prosumers by selling and buying electricity and thus generating income and solar entrepreneurship.

\section{CONCLUSION}

Our analysis provides a historic overview of the Bangladesh solar electrification program. The public entity IDCOL has been proven to be highly effective as a single aggregator for financing, standardizing and deploying SHSs on large scale in rural Bangladesh. Based on their policies, the key challenges of last mile distribution - financing as well as delivery of 
affordable, but high-quality SHSs combined with effective customer service - could be solved. The program's policies combine an attractive ownership model of the SHS for the end-user, affordable consumer loans as well as a highly enforced and developed local distribution and domestic supply side, which are incentivized by subsidies and soft loans. A local solar industry has emerged. Local manufacturing and distributors employ more than 100,000 people nowadays. Our institutional analysis identifies a well-structured division of the dimensions production, distribution and financing between the multiple stakeholders. The public sector, represented by the infrastructure agency IDCOL, is coordinating the policy level and managing the financial dimension of the program, while the production is in the hands of private manufacturing company. The provision is organized as a hybrid public private partnership model, which is characterized by MFIs, NGOs and social for-profit enterprises. In regards to swarm electrification, the facilitation of grid-like infrastructure for end-users should not be perceived as a competition to the national utility and the POs, but rather as an opportunity - on the one-hand, POs can tap into their existing SHS installations and stimulate consumption, productive use and entrepreneurship by repurposing and reallocating electricity usage at community level. On the other hand, as the P2P swarm microgrids grow towards the national grid, they can become the optimal service provider; the surplus electricity of each standalone solar system could be traded by the participants in the swarm grids.

\section{REFERENCES}

[1] Khandker, S.R., Samad, H.A. Sadeque, Z.K.M., Asaduzzaman, M., Yunus, M. \& Haque, A.K.E., Surge in Solar-Powered Homes, World Bank: Washington, 2014.

[2] Bangladesh Bureau of Statistics, Report of the Household Income \& Expenditure Survey 2010, Bangladesh Bureau of Statistics-Ministry of Planning: Dhaka, 2011.

[3] World Energy Outlook Team, Energy Access Outlook 2017: From Poverty to Prosperity, International Energy Agency: Paris, 2017.

[4] REN21, Renewables 2017 - Global Status Report, Renewable Energy Policy Network for the 21st century: Paris, 2017.

[5] World Bank, Tracking SDG7: The Energy Progress Report, World Bank: Washington, 2018.

[6] Briceño-Garmendia, C., Smits, K. \& Foster, V., Financing Public Infrastructure in Sub-Saharan Africa, World Bank: Washington, 2009.

[7] Beckers, T., Gizzi, F. \& Jäkel, K., Ein Untersuchungsansatz für Systemgüter: Einordnung, Darstellung, Vorgehen bei der Anwendung. TU Berlin/WIP-Working Paper, 2012-01, 2012.

[8] Hassheider, H., Die Bereitstellung Überregionaler Straßeninfrastruktur - Eine Institutionenökonomische Analyse der Optimalen Organisationsform und -größe, Vandenhoeck \& Ruprecht: Göttingen, 2005.

[9] Ewers, H.-J., Privatisierung der Bundesautobahnen, Vandenhoeck \& Ruprecht: Göttingen, 1995.

[10] Ménard, C. \& Saleth, R.M., The effectiveness of alternative water governance arrangements. Towards a Green Economy, ed. M. Young, Routledge/United Nations Environment Program: Paris, 2012.

[11] Ménard, C. \& Shirley, M.M., Handbook of New Institutional Economics, Springer: Dordrecht, 2005.

[12] Hankel, L., Finanzierungs und betreibermodelle für netzferne elektrizitätsversorgungssysteme mit photovoltaik: Institutionenökonomische analyse in subsahara-Afrika. TU Berlin/WIP-Working Paper, 2014. 
[13] Klatt, J.P., Eine Institutionenoekonomische Analyse von Finanzierungslösungen für die Bundesfernstraßen, Nomos: Baden-Baden, 2011.

[14] Wealer, B., Seidel, J.P. \& Hirschhausen von, C., Decommissioning of nuclear power plants and storage of nuclear waste. The Technological and Economic Future of Nuclear Power, eds R. Haas, L. Mez \& A. Ajanovic, Springer VS: Wiesbaden, 2019.

[15] Martinot, E., Cabraal, A. \& Mathur, S., World Bank/GEF solar home system projects: experiences and lessons learned 1993-2000. Renewable and Sustainable Energy Reviews, 5(1), pp. 39-57, 2001.

[16] World Bank, Project Appraisal Document. Rural Electrification and Renewable Energy Development, World Bank: Washington, 2002.

[17] Sadeque, Z., Rysankova, D., Elahi, R. \& Soni, R., Scaling Up Access to Electricity: The Case of Bangladesh, World Bank: Washington, 2014

[18] Asaduzzaman, M., Yunus, M., Haque, A.K.E, Azad, A.A.M., Neelormi, S. \& Hossain, M.D.A., Power from the Sun: An Evaluation of Institutional Effectiveness and Impact of Solar Home Systems in Bangladesh, Bangladesh Institute of Development Studies/World Bank: Dhaka, 2013.

[19] Bertsch, N. \& Marro, P., Making RE a success in Bangladesh: Getting the business model right. ADB South Asia Working Paper Series, 41, pp. 1-39, 2015.

[20] Tiedemann, S., The Bangladeshi solar home system (SHS) Programme: Relevance and development of the supply side. CISD Yearbook of Global Studies, 2, pp. 214-243, 2015.

[21] IRENA, Renewable Energy and Jobs: Annual Review 2016, International Renewable Energy Agency: Abu Dhabi, 2016.

[22] IRENA, Renewable Energy and Jobs: Annual Review 2017, International Renewable Energy Agency: Abu Dhabi, 2017.

[23] IRENA, Renewable Energy and Jobs: Annual Review 2018, International Renewable Energy Agency: Abu Dhabi, 2018.

[24] Sanyal, S., Prins, J., Visco, F. \& Pinchot, A., Stimulating Pay-As-You-Go Energy Access in Kenya and Tanzania: The Role of Development Finance, World Resources Institute: Washington, 2016.

[25] Wimmer, N., Green Energy for a Billion Poor: How Grameen Shakti Created a Winning Model for Social Business, MCRE-Verl.: Vaterstetten, 2012.

[26] Tyabji, N. \& Chase, J., IDCOL-lapse: the unmaking of an Off-Grid Solar Market, Bloomberg New Energy Finance: New York, 2016.

[27] Kebir, N., Spiegel, N., Schrecker, T., Groh, S., Scott, C. \& Aliaga Ferrufino, G., Exploring Energy SME Financing in Emerging and Developing Countries, Sustainable Business Institute: Oestrich-Winkel, 2013.

[28] UN, UN awards US \$1 million for Bangladesh solar entrepreneurship initiative to aid rural electrification, United Nations Department of Economic and Social Affairs. www.un.org/development/desa/en/news/sustainable/2017-energygrant-winners.html. Accessed on: 19 May 2019. 